\title{
Geotechnical Risks through the use of Geographic Information System in the Urbanized Area of the Upper City of Antananarivo Madagascar
}

\author{
Andriamalala Anjaramanantenasoa Nirina Miraniaina1, Goodary Rajeshwar², \\ Ratoarivelo Manitriniala ${ }^{1}$ \\ ${ }^{1}$ Institut Supérieur de Technologie d'Antananarivo \\ RN2 - Ampasampito,101 Antananarivo, Madagascar. \\ miraniaina2@yahoo.fr / mratoarivelo@gmail.com \\ ${ }^{2}$ Université des Mascareignes \\ Avenue de la Concorde, Roches Brunes, Rose Hill, Mauritius. \\ rgoodary@udm.ac.mu
}

\begin{abstract}
The Upper City of Antananarivo, is one of the districts of the capital of Madagascar subject to the regulations of the Architectural, Urban and Landscape Heritage Protection Zone [1]. On the other hand, the urbanization of this zone has not made it possible to curb the uncontrolled urbanization which is characterized by the spontaneity of illicit constructions caused in particular by the impoverishment of the local populations. Faced with this situation, the sanitation aspect of the area is no longer under control and all these phenomena have created a new type of exposure to risk through the degradation of the supporting soil and the triggering of fatal land movements. This urbanized area is subject to geotechnical risks that require reconnaissance on geological structuring, urbanization and problems observed to monitor the evolution of hazards. Technical studies of the Antananarivo upper town massif reveal instability and eventually hazards such as landslides, rock falls and block falls. These rapid phenomena expose local populations to new risks. As such, the consideration of risk management in this area and its mapping using Geographic Information Systems (GIS) is vital.

The objective of this paper is to draw up maps of urbanization and geotechnical hazards in the area concerned in order to monitor the evolution of risks and to alert the populations to the danger that may occur. Results of the research will provide operational solutions, especially in the decision-making process of local authorities regarding the evolution of these hazards and the sporadic evolution of housing in the upper city of Antananarivo, leading to the implementation of a continuous monitoring system, with alarm triggering on threshold detection - the Early Warning System.
\end{abstract}

Keywords: Geotechnical risks, land movements, instability, Geographic Information Systems, Early Warning System.

\section{Introduction}

This topical research allows to evaluate the progression of land movements, sometimes fatal, on the urbanized and very popular sites of the upper city of Antananarivo, and for the decision-making by local authorities.

The upper town of Antananarivo is part of the Analamanga region in the province of Antananarivo. It is a hill which culminates at more than 1400 meters of altitude. Its surface is about 80 hectares and its geographical coordinates are: S18 55 20 E47 31 58. It is surrounded by a buffer zone of 170 hectares [2].

The following maps help locate this part of the upper city of Antananarivo
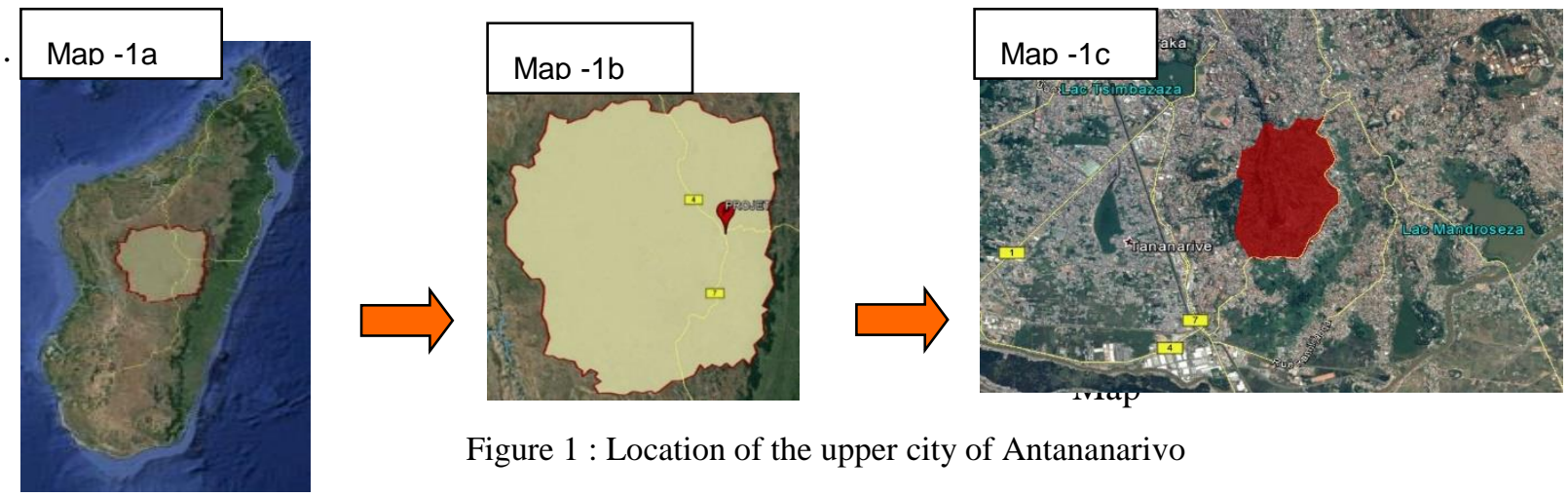

Figure 1 : Location of the upper city of Antananarivo 
The Upper Town is a site of exceptional quality. It is an urban site of great heritage quality, both in terms of its architectural buildings and its landscape location [1] and the urbanization of the city of Antananarivo has undergone a great evolution during recent years. This evolution is due both to the limited possibilities of extension, to the topography of the site and the occupation of the land, which was done in such a way, so as to make it more accessible to the public: anarchic as well as informal in terms of construction and land use, regardless of promiscuity and location.

All these modes of urbanization and the physical characteristics of the land lead to several hazards, the most frequent and the majority of which are landslides. Block falls are rare but have very deadly consequences. This combination constitutes the geotechnical risk which is explained in this paper later and methods of its assessment and management have been dealt with.

\section{Methods}

Geotechnical risk management in the upper city of Antananarivo requires the identification of the site, the monitoring of the site and the monitoring of the geotechnical risks. So, to be able to establish the geotechnical risk map, we need to know the physical characteristics of the site as well as a grouping of the different types of ground movements.

\subsection{Physical Characteristics}

\section{- Site geological formation}

The relief of the upper town of Antananarivo is complex, consisting of the tectono-magmatic and metamorphic formation: a set of rock formations of granite migmatite and granitoid migmatite and loose silty materials dominant on the surface.

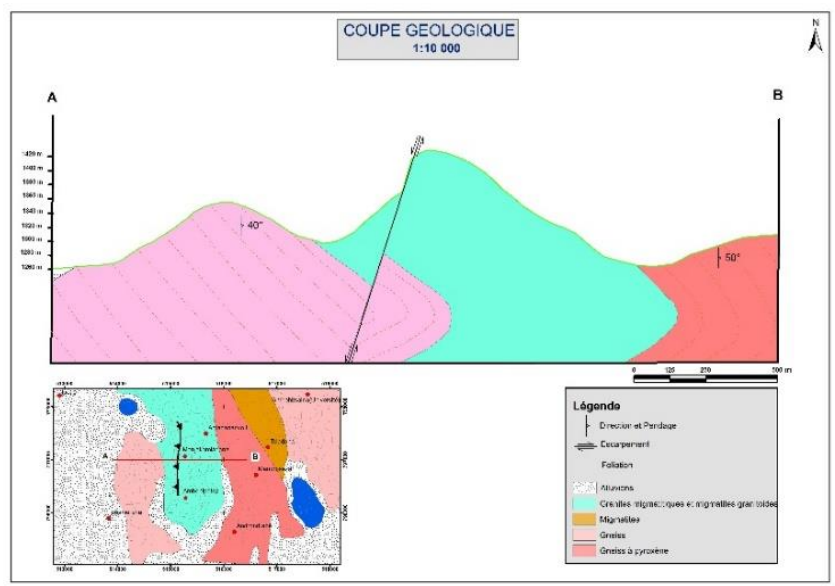

Figure 2: Geological map of the Upper City of Antananarivo and its surroundings by GIS

\section{- Pluviometry}

According to these established rainfall data, the average rainfall varies between 800 and $1500 \mathrm{~mm}$ annually.

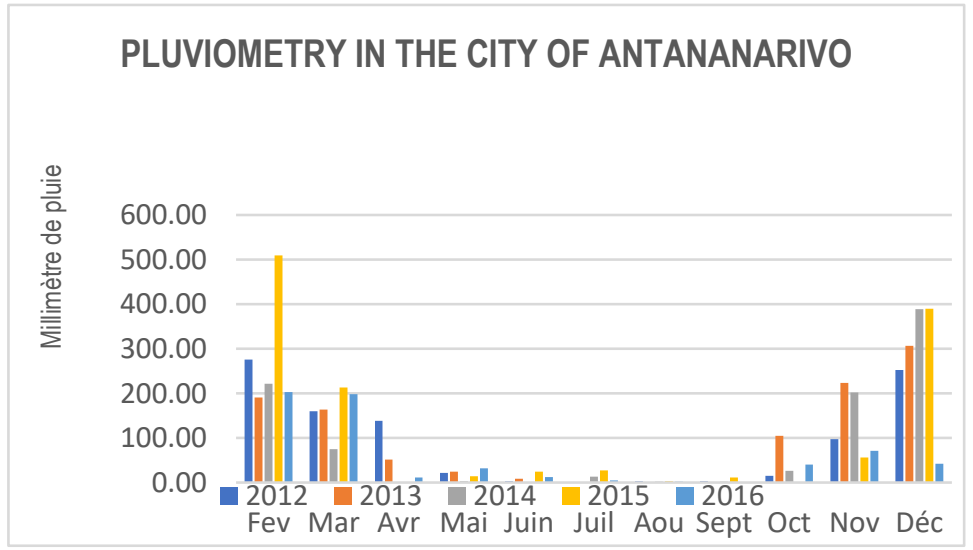

Source: General Directorate of Meteorology

Figure 3: Rainfall in [mm] for the city of Antananarivo. 


\section{- Site Hydrogeology}

The study site belongs to the high grounds "Hauts-Plateaux" hydrological zone, presented in the following map.

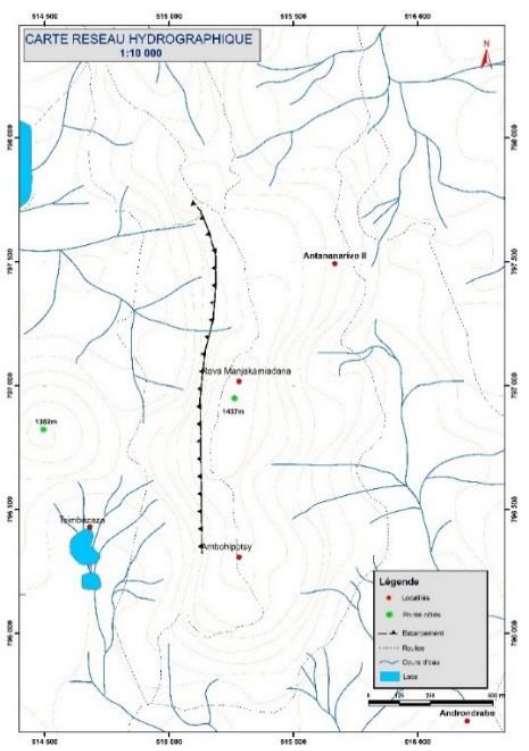

Figure 4: Hydrographic network of the upper town of Antananarivo, by GIS

\subsection{Geotechnical Hazards}

A geotechnical hazard is the possibility that a place or site may undergo a geotechnical phenomenon (landslide, block fall, etc.). During the investigation, surveys were conducted and instability indices were observed on site to properly specify the geotechnical hazards of the HAV, including landslide and falling blocks.

\section{- Landslide phenomena}

Several signs of instability were identified in the area of investigation: pull-out niches, inclination of trees, cracking of infrastructures, collapse of the retaining wall, deformation of structures and erosion of fines. These indices are signs of instability prior to landslide phenomena [7].

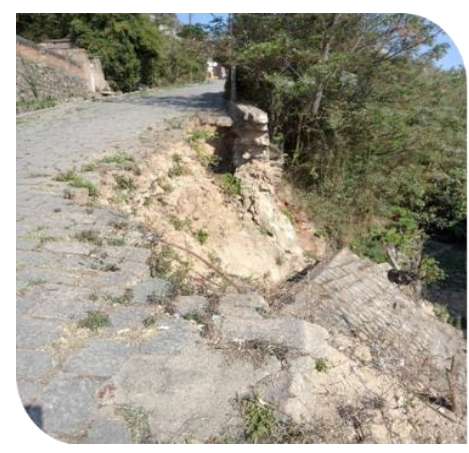

\section{- Falling Blocks}

Figure 5: Signs of instability (triggering landslide).

The natural evolution of cliffs and rocky slopes results in rock and boulder falls or mass landslides [5]. The characterization of morphological indices related to boulder fall phenomena is based on the identification of several parameters such as the type and size of the rock face, its slope, its geological nature, its texture as well as the unstable dihedral 
and boulder encrustations in the slope. Here are some clues to predict boulder falls among many others that we have observed in-situ.

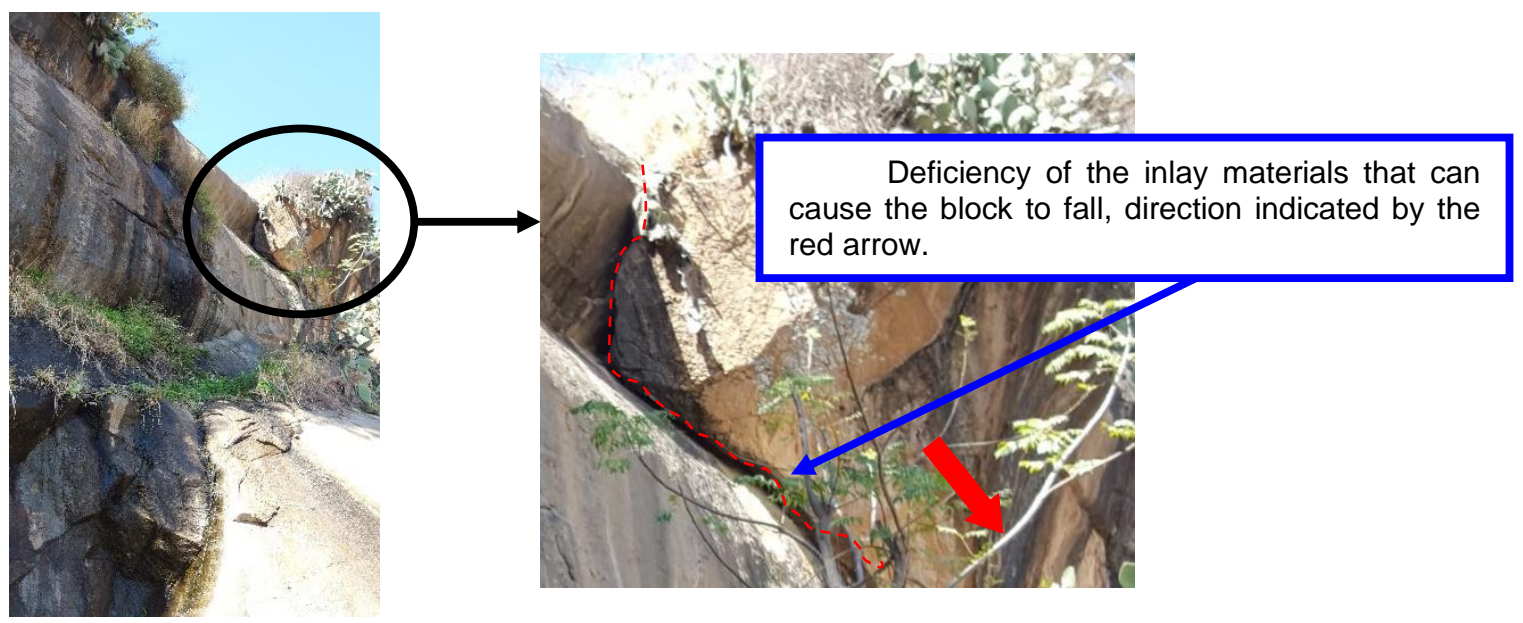

Figure 6: Presence of loose blocks

\section{Results and discussions}

Scientific studies have been carried out to determine the geotechnical characteristics of the loose formation subject to slippage in this area as well as the stability of the slopes.

The presence of unstable dihedron in the rock face is a significant indication of the "boulder fall" hazard. This index is particularly found as soon as the rock is fractured and where there is a visible presence of water. Boulders become loose from the rock matrix, which constitutes major risks for the inhabitants in the surrounding area.

First of all, the representation of the different maps such as the geological map, topographic map, hydrological map is first established from the Aerial Photograph of the site and the available data.

\section{Geotechnical risk map and Land use map}

The data of the field investigations combined with the processing of the maps with ArcGis software allows to obtain the following results: map of geotechnical risks and land use at different periods for the upper city of Antananarivo [8]. 


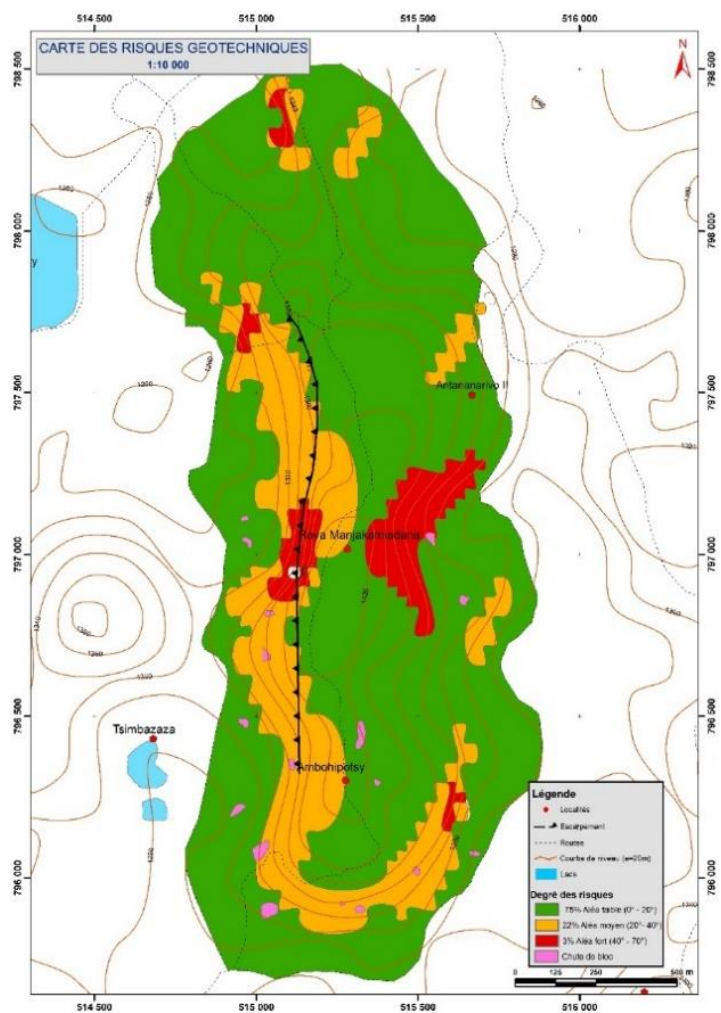

Figure 7: Geotechnical risk map of the upper city, by GIS

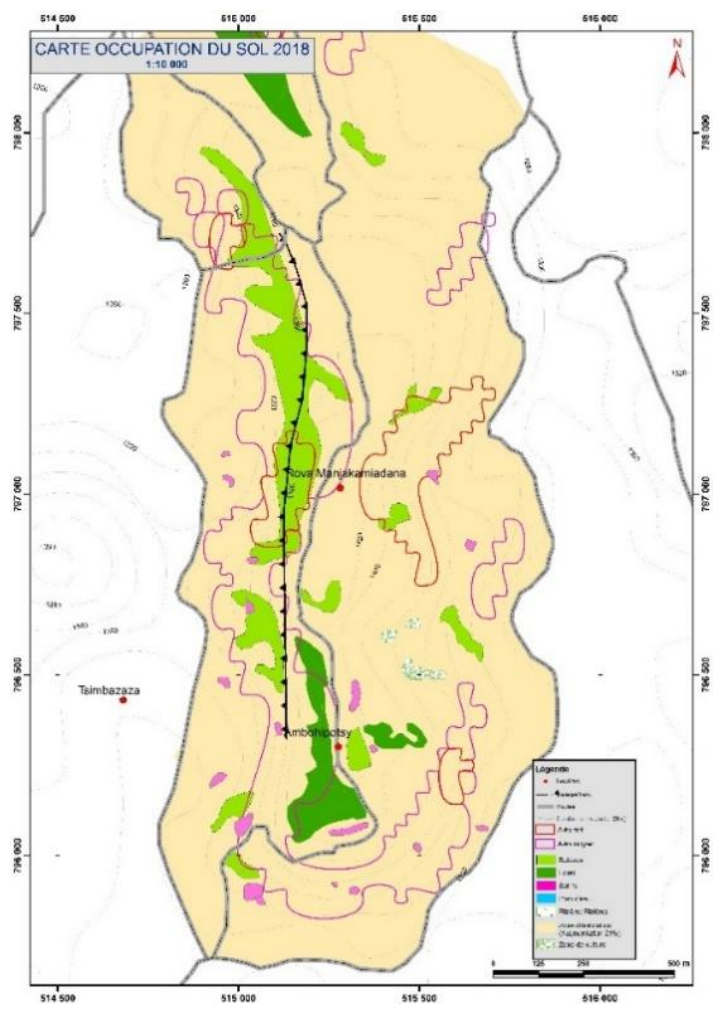

Figure 8: Land use map of the Antananarivo, by GIS

This research shows the potentialities of combining in-situ investigation and spatial analysis (scale: $1 / 10$ 000) to estimate the landslide risk. It complements the investigations already started by other organizations.

From the different stages, the geotechnical risk and land use were identified and mapped by combining several data:

1. collection of geographical, geological, hydrological and urbanization data for the upper city of Antananarivo;

2. field investigations to record ground movement indices and carry out geotechnical tests in the laboratory;

3. aerial photography using the drones.

\section{Conclusion}

In geotechnics, it is necessary to accept the uncertainty, the heterogeneity of the soils, the importance of field data, and to adapt the design of the structures to it; it is also necessary to identify as soon as possible the geotechnical risks to be incurred and to insert them in the risk analysis.

In this research, it is shown that the topographic, hydrogeological and geotechnical characteristics of the site will inexorably tend towards an unstable urban environment. It is fundamental to manage the geotechnical risks in the upper city of Antananarivo because it can help to set up a rational land use policy, and above all can save human lives. In this case, an answer to the following open question can be found:

"Does the urbanization mode of the urbanized area constitute a factor of amplification of risks of natural origin linked to ground movements?".

\section{References}


[1] Ministère de la Culture et de l'Artisanat de Madagascar (2016). La Haute Ville d'Antananarivo. [Online]. Available: https://whc.unesco.org/fr/listesindicatives/6078

[2] Madagascar Island (2002) [Online].

Available: https://www.madagascar-island.com/antananarivo-ville-haute

[3] Antoine Denis, Initiation_SIG_Arc_GIS, Arlon Campus Environnement. Université de Liège, Belgique (2012). [Online]. Available :

https://www.academia.edu/19839862/Initiation_SIG_Arc_GIS_Arlon_Campus_Environnement

[4] Bendeddouche H. and Lazizi S, Glissement de terrain et de confortements, Copyright Pages Bleues Internationales, 2013.

[5] Alp'Géorisques (2019) Chute de blocs et éboulement. [Online]. Available : http://www.alpgeorisques.com/chutes-de-blocs- et-eboulements.html

[6] Fayssal Cheriet and Hosni Taleb, Analyse d'un glissement de terrain avec la méthode des éléments finis et celle d'équilibre limite, Editions universitaires européennes, 2018.

[7] Miraniaina Andriamalala, «Etude de la stabilité des terrains naturels, calcul de la stabilité cas de la route nationale $\mathrm{n}^{\circ} 2$ du PK 50 au PK 200 » DEA. Dissertation, Dept. Science des matériaux, Ecole Supérieure Polytechnique, Antananarivo, Madagascar.

[8] A Hillier, "Manual for working with ArcGIS 10", FTP Directory Listing, 2011. 